\title{
The Complexity of 'Community': Considering the Effects of Discourse on Museums' Social Media Practices
}

\author{
Amelia Wong *
}

\begin{abstract}
Words are 'objects of discourse' in that they function not simply to convey meaning, but also to assert and reinforce values and truths in a society. Here I consider the effects of 'community' as a discursive object in museums' use of social media, since how it is imagined affects practice, especially how institutions try to democratize practice. I trace a genealogy of 'community' to show how museums translate long-held ideas into new practices, explaining how its origins and social media conventions influence museums to champion an idealized view of community based on frequent, public, and immediate communication. Using the case study of the Japanese American National Museum's Discover Nikkei project, I argue that, while communication is essential to progressive practice, museums accepting this conceptualization can actually stymie their efforts to use social media to democratize their relationship with audiences. I conclude with suggestions as to how to address this issue.
\end{abstract}

Keywords: community, communication, social media, democratization, discourse

\section{Introduction}

Museums have a long history of evoking 'community' in the interest of democratizing relationships with users. This tendency may be traced to the concept's origins in the Greek polis-the original model of pure democracy. Consequently, museums typically accept it as a self-evident good-virtuous and worthwhile in and of itself-and therefore a quick fix to correct the role they have played in imperialism and social oppression, as well as to address charges of elitism or irrelevancy. They thus also have a long history of not defining community (Karp et al. 1992; Barrett 1998; Crooke 2007; Watson 2007). These habits continue today in museums' adoption of social media. Because how we imagine community affects practice, and most significantly, how we imagine community affects the ways we try to democratize practice, in this article I consider what community means in museums' uses of social media.

Community is a powerful concept in Western society in that it enjoys intensely positive connotations. At the same time, it is deeply ambiguous and can mean many different, even opposing, things. In order to consider how it affects modern museum practice, I approach it here as an object of 'discourse.' By discourse, I don't mean simply language or conversation, but the post-Structuralist concept that encompasses all of the ways we communicate-speech, gesture, stamps, pottery, video games, etc. Texts like these produce and reproduce culture, circulating values and truths throughout a society. Discursive objects like community inform people's decisions and actions. For instance, in the early years of the web, people debated whether 'community' could exist online (Jones 1998; Shumar and Renninger 2002; Wise 2003). Twenty years later, the question appears moot; community is virtually everywhere. This shift occurred with the emergence of 'social media,' currently the favored term for the proliferation of digitally networked sites, applications, and tools that encourage and facilitate social interaction, communication, and information exchange. That a rhetoric of community suffuses these media, voiced by the people, companies (Jansen et al. 2009), and non-profits (Lovejoy 2012) that make and use them, is not surprising, but is quite telling. Following the typical trajectory of the introduction of any new technology into everyday life, the popularization 
of networked digital media in the early 1990s generated a great deal of anxiety about their potential impact on social life (Baym 2010: 22-49). Some of this anxiety subsided as people became accustomed to using and manipulating these media. This period of acculturation saw community become the chosen word to describe social relations online, whether real, potential, or desired. This occurrence expresses the depth of meaning that community enjoys in Western life-as sociologist Gerard Delanty puts it, 'Community exerts itself as a powerful idea of belonging in every age, and as such its reality consists of its persuasive power as the most 'social' aspect of society' (2003: 11). It also expresses how community has been used time and again as a defensive measure, signaling an effort to convey boundaries and safety in uncertain times (Bauman 2001).

Looking closely at how people utilize a complex and ambiguous term such as community reveals much about their hopes and fears, about the decisions they make and the actions they take. It also builds on the considerable amount of scholarship that has critiqued community, networked digital media generally, and social media specifically, as not inherently virtuous or democratic constructs. Drawing on that body of criticism, especially literature that challenges the valorization of face-to-face communication (Young 1986; Kolko and Reid 1998), I trace a genealogy of 'community' here to show how museums translate long-held ideas into new practices, explaining how its origins and social media conventions influence museums to champion an idealized view of community based on frequent, public, and immediate communication. Using the case study of the Japanese American National Museum's Discover Nikkei project, I argue that museums accepting this conceptualization can actually stymie their efforts to use social media to democratize their relationship with audiences. ${ }^{1}$ I conclude with suggestions as to how to address this issue.

To be clear, communication between museums and audiences is essential to progressive practice. But an overly simplistic view of that communication motivates museums to base success on high degrees of public participation, which research shows is neither the norm for online user behavior nor necessary for creating value for the majority of users. These unrealistic expectations encourage museums to design projects that don't always serve user needs or museum goals, and rely on unrealistic evaluative criteria. As Angelina Russo and Darren Peacock (2009) have noted about museums' perspectives on participation in social media in general, the emphasis on community is 'the result of a conflation of organisational [sic] objectives with those of users.' Like them, I want to encourage museums to better account for user preferences in their social media practice, in order that they can actually better serve their goals of audience participation.

\section{What Community Can Mean}

Museums use 'community' to refer to many things in many contexts. They use it in promotional language, marketing research, educational programming, and to refer to museum professionals as a group. Each use expresses a different combination of ideas: face-to-face conversation, tradition, identity, place, shared interest, grass-roots activism, the collective good, the 'public sphere,' amateurism, everydayness, and 'the people.' Museums also employ community as a euphemism for people of color and for inner-city populations. Sometimes it expresses how museums want to be seen as part of communities, sometimes to express how they are separate from them. Whatever they mean it to convey, museums tend to view community as a self-evident good because it has democratic connotations (even if their intentions aren't always genuine). Consequently, community may be understood as a strategy museums use to legitimate their actions.

How does this work? First, a celebratory discourse surrounds community. As Raymond Williams observed, 'unlike all other terms of social organization,' community 'seems never to be used unfavourably, and never to be given any positive opposing or distinguishing term' (1983: 76). Western conceptions infuse community with idealistic social and civic connotations. Imagined as a self-governing group of peers, community is held up as the apex of social life and as the truest expression of citizenship.

Second, community enjoys an apparently depthless symbolic capacity. Sociologist Anthony Cohen argues that community's power rests in its ability to represent other things, to act as a symbol. Symbols: 
[...] are almost impossible to spell out with precision. [...]But their range of meanings can be glossed over in a commonly accepted symbol - precisely because it allows its adherents to attach their own meanings to it. They share the symbol, but do not necessarily share its meanings. Community is just such a boundary-expressing symbol. As a symbol, it is held in common by its members, but its meaning varies with its members' unique orientations to it (1985: 15; orig. emph.).

Such orientations may be revealed by considering the meanings and ideas community has accrued over several centuries and among scholars, in political movements, and in society in general.

In Community (2003), Delanty explains how conceptions of community have evolved from assigning people to groups (community as 'thing') to expressing feelings of belonging (community as 'process' or 'experience'). His survey offers a framework for understanding the concept's complex history. These meanings, which overlap, cohere around various ideas: utopia; an alternative to society and modernity; locality; political citizenship; multiculturalism; and communication. Though all of these meanings find parallels in museum practice (Crooke 2007; Wong 2011), I concentrate on those most pertinent to this discussion: utopic constructions, especially the polis; locality; and communication.

The positive spin community enjoys may be traced to its two earliest conceptions, which have come to be seen as versions of utopia. The polis-the 'political community' of the ancient Greeks - provided 'the basic ideal for all subsequent conceptions of community' (Delanty 2003: 12). In a culture that did not conceive the social and political as separate, the polis was realized when the citizens of a city-state gathered in a shared locale and practiced self-government by talking about political matters. Meanwhile, Christian thought envisioned a 'universal community' based on 'communion with the sacred.' Human society was to be transcended or rejected (ibid.: 13-14). These seeds give community its inherent tension: the Greek polis and the Christian 'universal community' established the concept's 'ambivalent' core, its 'double sense' that simultaneously connotes the local and universal, the specific and general, exclusion and inclusion (ibid.: 12). At the same time, these notions established community as intrinsically good and democratic. The polis also inextricably linked community to public and face-to-face dialogue.

In more recent centuries, scholarship prompted a cultural turn in understanding community in terms of shared places, traditions, heritages, and identities. This view saw the 'thick' ties of tradition and heritage that were maintained by frequent interaction as supporting community (Delanty 2003: 28). The importance placed on public and frequent conversation remained as scholars like the urban sociologists of the Chicago School defined community in terms of neighborhoods (the city's equivalent of small towns) and the sense of belonging that comes from people living in close proximity (55). Their work also asserted communication as a significant aspect of democracy by recognizing that one way marginalized groups could advocate for resources was to publicly voice their experiences and opinions (71).

This evolution describes how meanings of community have become increasingly fluid, but always entwined with communication. Delanty argues the dominant form of community today is that of a communicative community. While '[community] has always been based on communication', that aspect of social relations has come ever more to the fore:

... contemporary community may be understood as a communication community based on new kinds of belonging. By this is meant a sense of belonging that is peculiar to the circumstance of modern life and which is expressed in unstable, fluid, very open and highly individualized groups. The communities of today are less bounded than those of the very recent past. The communicative ties and cultural structures in the contemporary societies of the global age - as opposed to in industrial and traditional societies - have opened up numerous possibilities for belonging, based on religion, nationalism, ethnicity, lifestyle and gender. It is in this world of plurality rather than of closure that the new kinds of community are emerging (2003: 187-188).

The versions of community apparent in scholarly and popular thought are all at work in the museum field, both explicitly and implicitly; they express a general evolution from community 
as 'thing' to 'process,' yet operate in tandem. Museums have probably been most dependent on community as identity, tradition, heritage, and place, but notably, over the twentieth century, community in museum work came to be closely linked to communication and collaboration, especially in efforts that sought to reform museums (Dana 1919). These activities were at the heart of the ecomuseum and community museum movement of the late 1960s and 1970s, and are exemplified by John Kuo Wei Tchen's idea of a 'dialogic museum,' which regards audience members as partners that participate in and shape a museum's practice. Establishing constant dialogue between staff and audience was understood not only to democratize practice, but as a way to empower visitors as historical agents and citizens-people who see themselves as actors in history may be encouraged to act in the present (1992: 291). Such ideas speak to how community in museum practice became interwoven with ideas about civic engagement, communication, amateurism, and resistance to dominant power structures. They also speak to how practitioners have reasserted the foundational idea of the polis, evident in the popular view of museums as agoras and forums (Archibald 2004; McLean and Pollock 2007) and of communities as active audiences, rather than passive observers (Karp 1992). That this idea remains powerful is exhibited in the way community is constructed as communication through social media.

\section{Community through Social Media}

Delanty's assertion that community today is largely imagined through communication is true in both museums and social media. Further, social media imagine community principally through frequent, public communication.

'Social visibility' is a key aspect of social media (Shirky 2008: 11). Whether the principle purpose of a social media platform is for users to connect and converse or collect, sort, and share media, it is 'social' because it allows users to make themselves visible to each other by externalizing their actions and thoughts. This emphasis on social visibility may be explained by our persistent reliance on publicity to constitute our sense of reality. In the words of Hannah Arendt, 'For us, appearance-something that is being seen and heard by others as well as by ourselves - constitutes reality' (1998: 50). Predictably, Westerners' acculturation to networked digital media expresses the cultural tendency to use technology to externalize internal thought (Manovich 1995). The externalization of identity and thought online amounts to the rematerialization of the physical body and world and the reassurance of reality. The emergence of social media in the early 2000 s may be read as a reaction-a proffered resolution, reallyto the anonymous nature of networked digital technology, an enduring source of anxiety for users and non-users alike. Early online interactions were text-based and largely anonymous, conditions that prompted concern about the potential for deception (Donath 1999). In response, users returned a sense of materiality to their identities and relations by '[typing] oneself into being' (Sundén 2003: 3) with elaborate descriptions of avatars and places, even reasserting the material world's rules of physics (Slater 2002).

Social media promote social visibility precisely to deal with the anxiety of not being able to 'see' other people online. In physical life, we rely on our senses and cultural knowledge to read cues that then influence our behavior. Online, social media push practices that materialize people in order to create a context of understanding that is otherwise absent. Profiles on social network sites '[amount] to an accessorized digital body' (Boyd 2006: n.p.). The public nature of social media reasserts the traditional role vision plays in influencing behavior (Foucault 1995). The assertion of material bodies in space gives us a sense of social order (Slater 2002). I suggest that seeing online social relations as community also helps people feel safer, since the traditional construction of the concept on the basis of communication promotes the materialization of online users. As Aaron Barlow describes it, the construction of community through the blogosphere mitigated 'the lonely void' of the web experience: it '[allows us to] become a "we" rather than an aggregate of "I"' (2008: 71).

Social media use conventions of language, design, and features to construct community. Each encourages users to make themselves visible to each other. Language circulates a discourse of community invested in public communication. Design conventions cultivate feelings about safe space in which that communication can take place. Interactive features suggest to users 
that they act simultaneously and in proximity with others by cultivating a sense of co-presence and immediacy. They encourage people to visually articulate their identities; to converse, share information, and take actions; and they privilege 'real time' information. By building community in such ways, they express people's continuing investment in basing community on frequent, public, and face-to-face communication - that is, on the ideal of the polis.

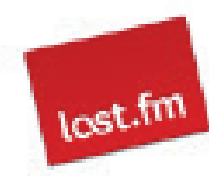

\section{Need new music?}

Last.fin lets you etfortlessly keep a record of what you listen te" from any plare?. Based on your taste. Last.fm recommends vou more music and concerts!

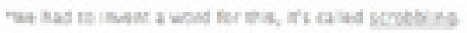

Sart vow profile
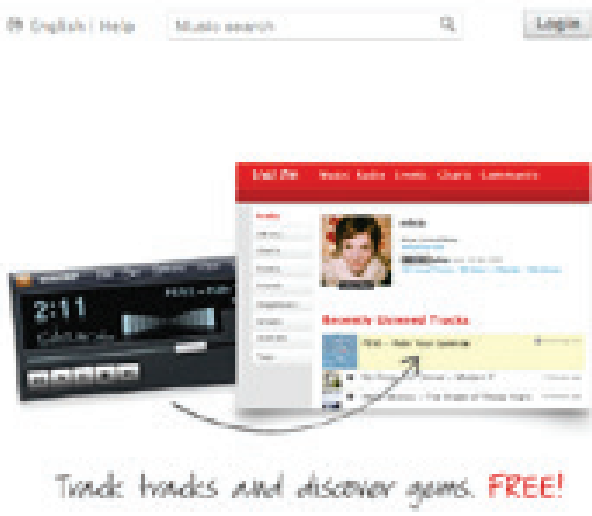

Figure 1. Screen capture of the homepage of Last.fm, accessed March 30, 2013. Courtesy of Last.fm

Social media employ language about community in several ways. Social media sites are often described as 'community sites' and frequently include 'community' as an option in global navigation (figure 1). Illustrating community's symbolic capacity, the options listed in a site's 'Community' tab are never completely predictable, but most point to the different ways users can communicate with each other and a company or organization. The 'Community' option on the website of content management system Drupal opens a page listing opportunities - online and local groups, events and meetups, internet relay chat, discussion forums and a blog aggregator-to meet, communicate and work with members of the 'Drupal community.' Under 'Community' on Discover's website, one finds only links to the financial company's presences on YouTube, Facebook, and Twitter. Social media sites also plainly describe how their communities are based on communication and interaction. The 'Community' page of Etsy, a popular website for buying and selling handmade and vintage goods, urges users to 'Connect with fellow Etsians' and aggregates options to interact, communicate, and collaborate, both online and off: 'Join a team, share ideas, attend an event in your area, join a streaming workshop or watch an archived one.' The tone of such language is consistently friendly and informal and often

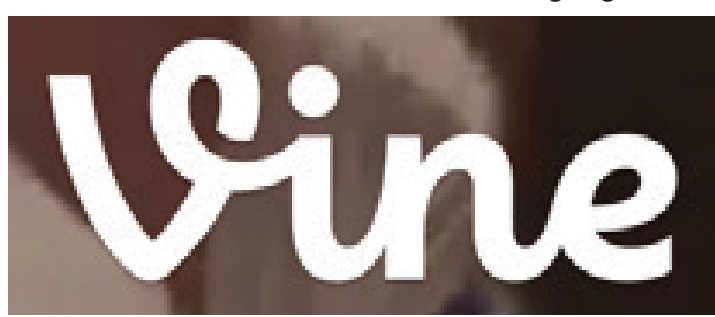

Figure 2 Screen capture of Vine logo, accessed June 28, 2015. The Vine logo is a trademark of Twitter, Inc. Courtesy of Twitter, Inc. uses slang. Such norms strive to create a sense of everydayness, welcome, and safe space.

The design conventions of social media echo those intentions. They typically make use of thick, rounded or curly fonts and often use only lowercase letters in logos (figure 2). Images are whimsical or increasingly feature gorgeous photography of people enjoying themselves (figure 3 ). The video-sharing site Vimeo provides a quintessential, if extreme, example. The background of Vimeo's first homepage and registration 


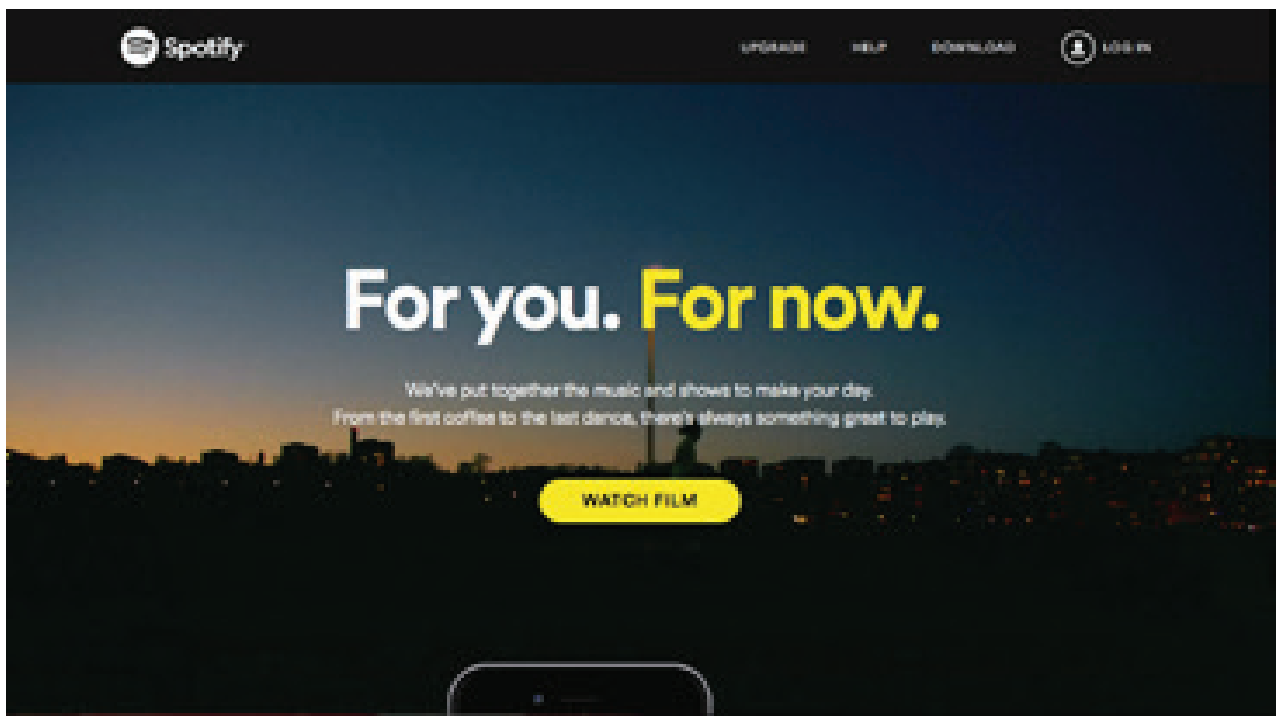

Figure 3 Screen capture of Spotify.com homepage, accessed January 18, 2014. Courtesy of Spotify

page illustrated an idyllic world, complete with shining sun, lush green grass, abundant water, a hot air balloon, a drive-in theater, grazing cows, a frolicking Pegasus, and people with various skin tones making movies (figure 4). It invoked community through nostalgic imaginings of small town life, represented as a peaceable kingdom of creative people living in harmony with animals and nature. (Its new homepage (launched January 2012) uses an illustration of fantastical creatures in a forest, where they can gather to make movies and watch them together (figure 5).)

Most importantly and most regularly, social media promote community by encouraging users to visibly articulate themselves and their networks through their participatory features: making profiles; publicly communicating; and privileging 'real time' interactions and information.

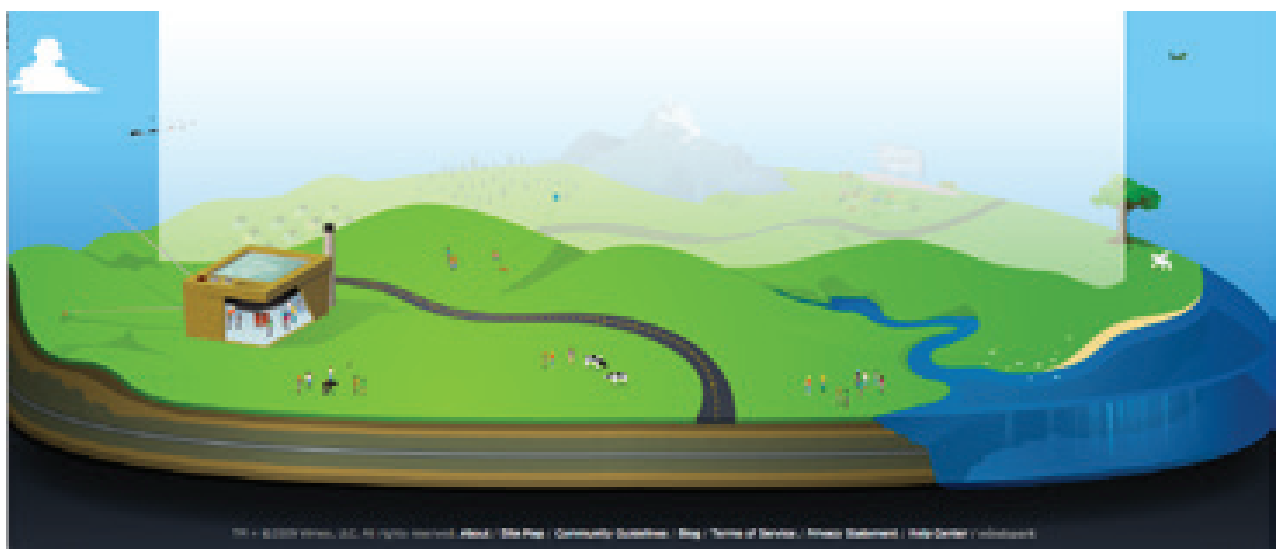

Figure 4 Screen capture of bottom section of the homepage of Vimeo.com, accessed November 11, 2009. Courtesy of Vimeo

The user profile is a defining aspect of social network sites, which are singularly invested in the materialization of users and networks. By building 'a public or semi-public profile within a bounded system,' '[articulating] a list of other users with whom they share a connection,' 


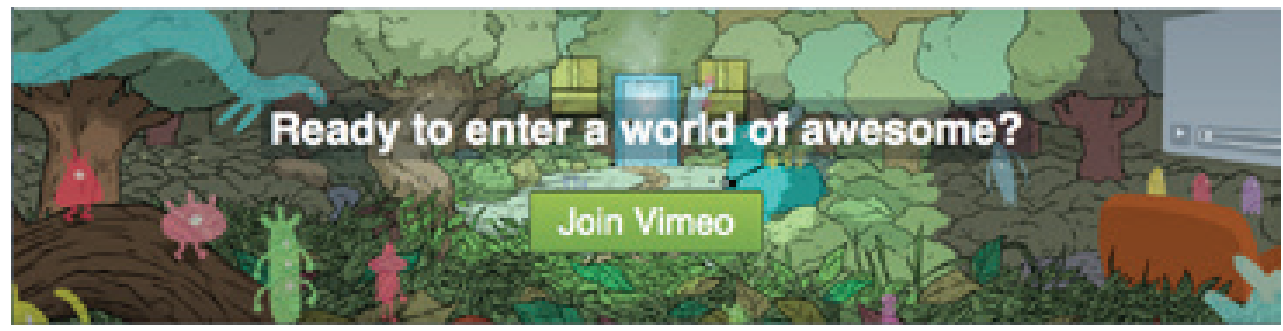

Figure 5 Screen capture of section of the homepage of Vimeo.com, accessed January 18, 2014. Courtesy of Vimeo

and '[viewing] and [traversing] their list of connections and those made by others within the system,' social network users materialize their bodies, identities, and relationships online (Boyd and Ellison 2007).

Social media sites in general ask users to make profiles, but they rely principally on encouraging public acts of communication, by which I mean both conversation and taking actions, to help users construct their identities and sense of community. Users endlessly confront solicitations to share, in Facebook's current phrase, 'What's on your mind?' People communicate their identities and realities when they take various actions: make comments; create a profile; upload and share links and media; rate or vote on content; 'tag' it; download it; 'favorite' or 'like' it.

Further, social media emphasize frequent communication to construct community, a tendency borrowed from communities manifested through proximity. They highlight current updates of information to cultivate a sense of urgency and change to motivate users to regularly check back at sites. They accomplish this by emphasizing recent activity on homepages and in user newsfeeds, and highlighting that this activity takes place in 'real time.' Benedict Anderson (1991) described how mass print culture played a role in constructing the 'imagined community' of modern nations by giving citizens a sense of simultaneity and shared experience. Similar to

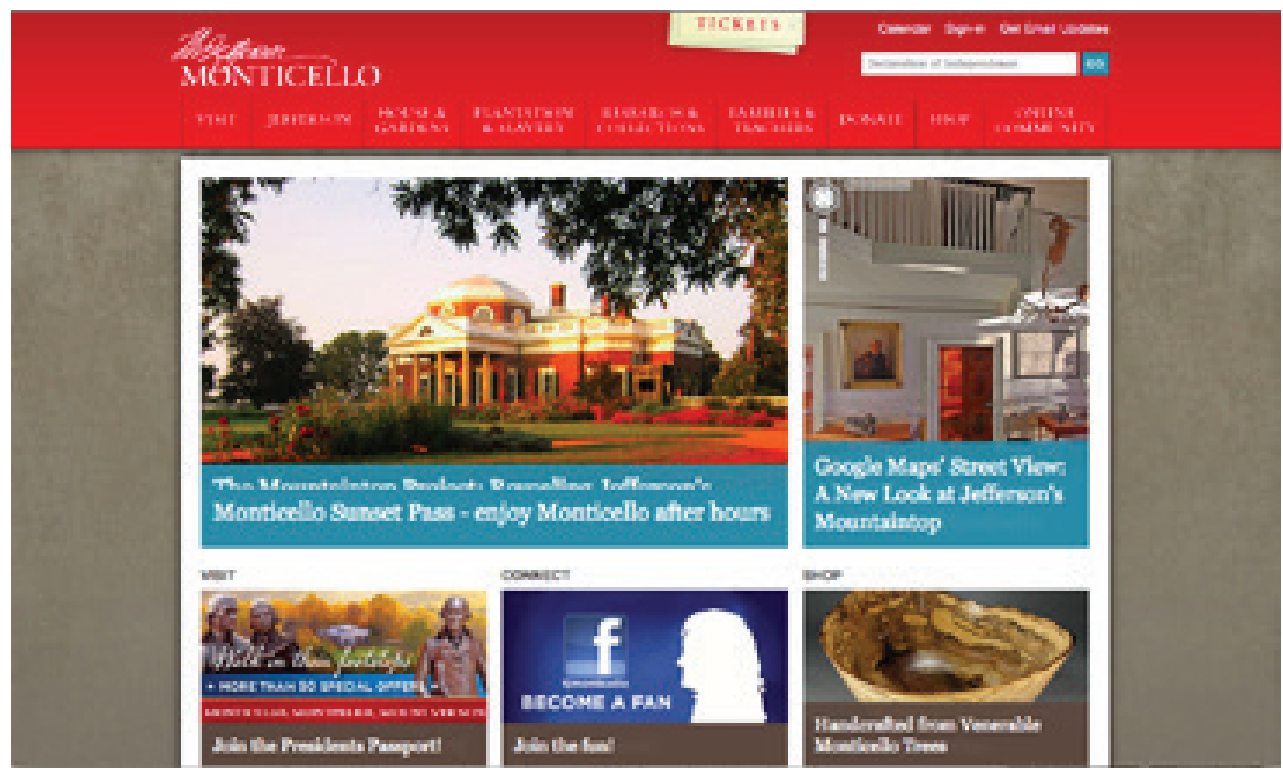

Figure 6 Screen capture of the homepage of Monticello.org, accessed January 18, 2014. Courtesy of The Thomas Jefferson Foundation 
how noting you and your neighbor on the bus are reading the same newspaper can reaffirm your sense of commonality with strangers, social media 'continually reassure that the imagined world is visibly rooted in everyday life' through even more powerful means (35-36). Updates about logged-in users and their actions on the homepages of Reddit and Library Thing are marked as happening ' 25 seconds ago.' In contrast to time-stamping messages, this method conveys how much time has elapsed from the present, which suggests the currency and endless flow of information. ${ }^{2}$ Knowledge that others are looking at this information on similar screens on similar devices also reinforces a sense of immediacy and simultaneity.

The myriad ways museums use social media to create and imagine community online follow the above conventions. Many include 'community' as a global navigational tab on their websites, which list a museum's social media accounts and other communicative options (figure 6). Others utilize language that attaches communication to community. The

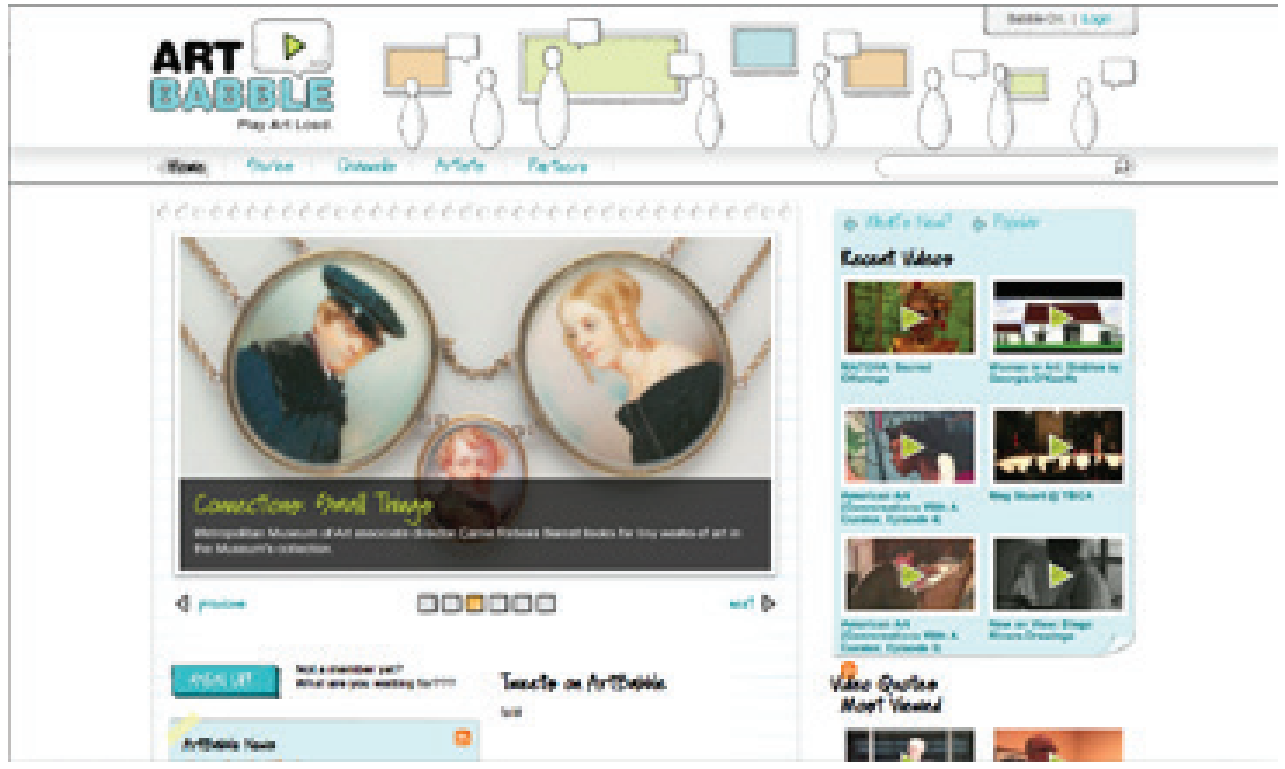

Figure 7 Screen capture of the homepage of ArtBabble.org, accessed March 30, 2011. Courtesy of the Indianapolis Museum of Art @ 2012 Indianapolis Museum of Art

'Community Center' link on the United States Holocaust Memorial Museum's Children of the Lodz Ghetto project explains users should 'Use this space to share discoveries, ask questions, form research groups, read about the history, and learn more about how to use this site.' The first design of the Indianapolis Museum of Art's Art Babble (a redesign launched in December 2012) incorporated typical elements of social media design: hand-scribbled font, a soft color palette, and the motif of speech bubbles (figure 7). Hundreds of museums create presences on external social network sites to encourage audiences to materialize themselves through following, posting and commenting. Profile-building features appear in in-house projects like the New Museum's Rhizome, which also emphasizes co-presence by highlighting 'recent activity' (figure 8).

All of these uses root community in frequent, public, immediate communication. They also express a cacophony of goals. Danah Boyd and Alice Marwick state that networked publics (a term l'll return to in the conclusion) 'can play a civic function, serving to gather people in a democracy. But they can also play a social role, enabling people to make sense of the world around them and understand their relationship to society' (2011). Community in social media operates in a similar way, conveying both civic and social ideas, though these are not discrete. Sometimes the use of community simply stands in as a warmer word for audience, conveying a marketing goal of making a museum sound friendly. Sometimes community is meant in a local 
sense, addressing the people who can regularly visit: the Please Touch Museum asks people to 'Join the community on our Facebook page and get access to lots of contests, discounts and to know about activities and programs before anyone else!' Museums may use the word to refer to communities of interest: the institutions that have joined the Flickr Commons project seek to share their collections with the public through a platform that attracts photography aficionados. That project also relies on the notion of community as a reciprocal and collaborative relationship, where people work together to accomplish a goal.

The looseness with which such projects throw around community can contribute to museums confusing their methods with their goals. Calling an audience a community doesn't make it so. Creating many options to communicate doesn't create more democratic conditions between museums and audiences. In the case of projects that aim to democratize relations with audiences, they may benefit by articulating their definitions of community so they can design participatory options that serve their goals and meet audiences' needs. An in-depth example will help illustrate this.

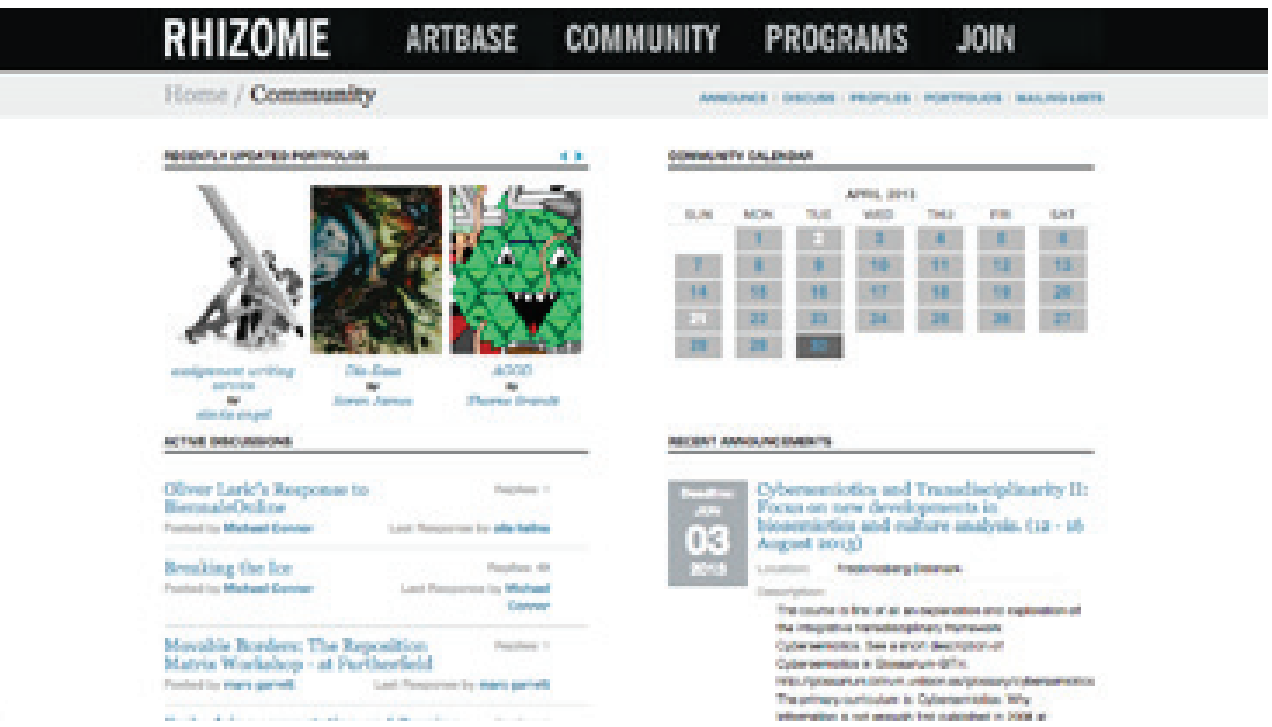

Figure 8 Screen capture of the 'Community' page of Rhizome.org, accessed June 1, 2013. Courtesy of Rhizome

\section{Community in Discover Nikkei}

The Japanese American National Museum (JANM) launched Discover Nikkei (DN) in late March 2005 as an outgrowth of the International Nikkei Research Project. ${ }^{3}$ The original project supported scholarly research and publications about 'the cultures and identities of Nikkei people of Japanese descent - living in the Americas,' with the goal of building a repository of Nikkei experience and community through global collaboration (Kikumura-Yano 2005: 195-96). When approached to extend the project, the funder preferred to support something that would make the research more accessible to a lay audience and proposed a website.

In 2009, former Project Manager Vicky Murakami-Tsuda led a total redesign of the site, with the aim of better encouraging and making visible 'community' and 'community-building relationships' than had its previous design. ${ }^{4}$ The project's mission, in part, inspired this emphasis. According to the website:

Discover Nikkei is an international network that celebrates cultural diversity and explores both global and local identities. The project connects generations and communities by sharing stories and perspectives of the Nikkei, people of Japanese descent who have migrated and settled throughout the world. 


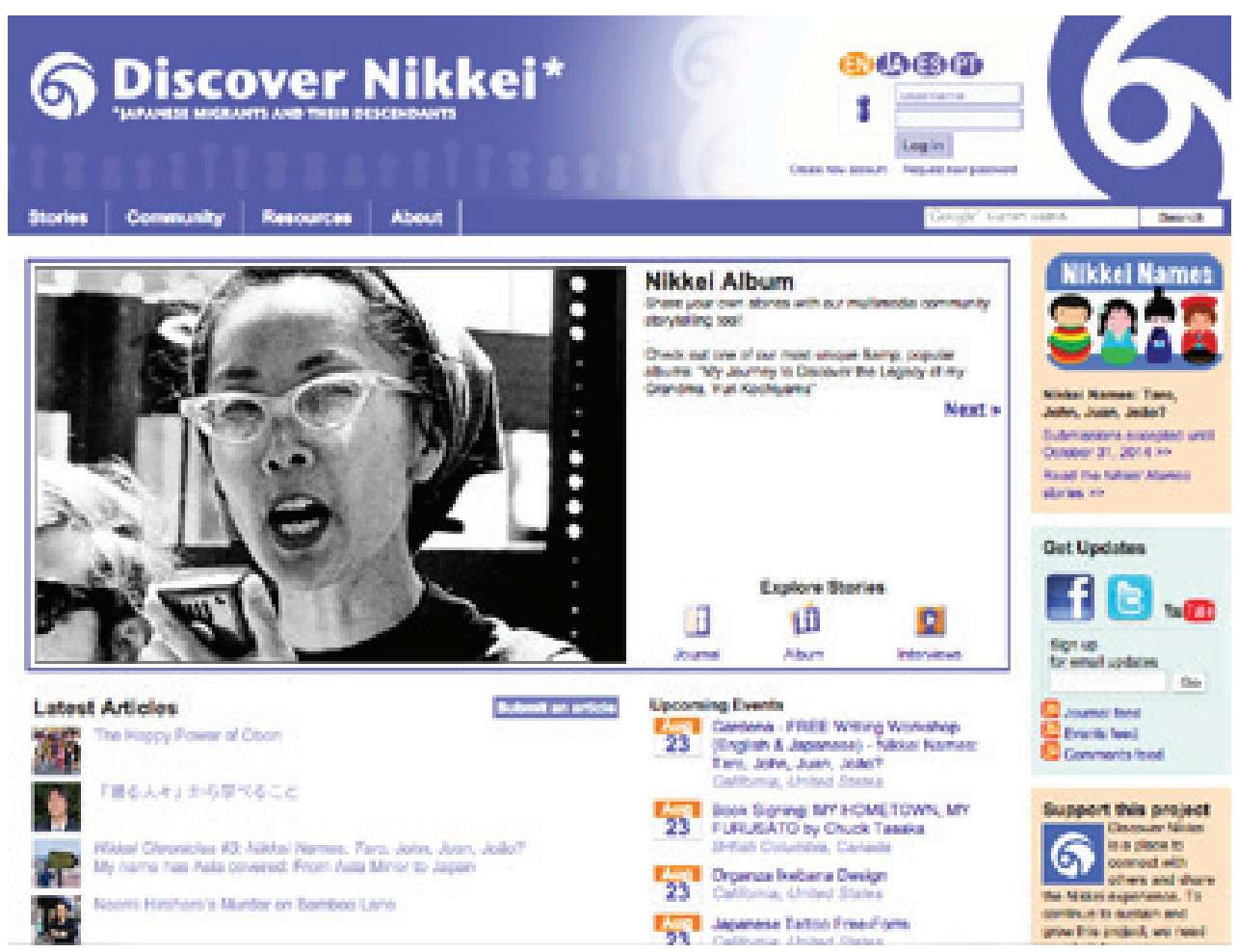

Figure 9 Screen capture of the homepage ofDiscoverNikkei (discovernikkei.org/en/), accessed August 22, 2014. Courtesy of the Japanese American National Museum (c) 2014 Japanese American National Museum

Another source of inspiration were the audiences that Murakami-Tsuda had determined through long observation got the most value out of the project: the small affiliate partners with lowtrafficked or non-existent websites and individuals 'who are personally interested and wanting to connect with others looking for similar experiences.'

Additionally, seeking a community of participants was in line with JANM's practice, which is invested in community history projects that depend on the contributions of people who lived that history (Kikumura-Yano et al. 2005). As a site that explores identity, Discover Nikkei seeks significant audience participation:

[... what] we're trying to do is provide a space where people, people in all these different communities can tell their own stories from their own perspectives, in their own voices. So, it's not the Japanese American National Museum saying, 'This is what the Nikkei experience is like in this, for this group of people.' It's that group, that person, or that community saying, 'This is our experience.'

Finally, the aim to involve audience members in the project served a practical as well as philosophical purpose. Despite a small endowment from the funder, the project lacks the financial resources and personnel to sustain it over the long term, and thus attracting a community serves technical as well as content goals:

We need to form a community that actively contributes to the site and feels ownership in it, and in that way we can keep the site vital without us having to have a lot of staff or have to pay writers to do it.

To encourage that investment, Murakami-Tsuda joined and used Facebook in order to figure out how it inspired regular use. This experience also informed Discover Nikkei's community aims: 
And what we are really hoping to happen through this new site redesign is more, sort of, organic, real sense, like in a real community. It's not, you know, one other person and one other person and one other person. Those other people know each other as well, right? And so, that's, you know, it's part of the social networking kind of thing. [...] And what we're hoping with the new site is that will happen a lot more, and actually, in more frequency.

These reasons for building Discover Nikkei expose several meanings and goals for community. There is the ethnic and cultural community of Nikkei, many of who share circumstances and experiences related to their racial and ethnic make-ups and heritage. There is also a community of interest, which shares a desire to learn about Nikkei experiences. The project also draws upon community defined as 'the people,' the public empowered to share their stories in their own words. Further, the staff imagine the ideal audience as a community of practice based on reciprocity and collaboration, in which users would build a culture of belonging, investment, and altruism through habitual visiting and adding and moderating content. Finally, there is a sense of the proximal and communicative community that bonds a network of people through frequent interactions. All of these meanings are apparent in the site itself.

Produced and maintained in-house at JANM, the DN website incorporates most of the trademark strategies of social media to build and represent community. Murakami-Tsuda intended the design, primarily blue and white punctuated by orange, to look more 'informal' than the previous design and organized the site's content in a more intuitive and straightforward manner (figure 9). The header and various pages prominently feature the pictorial motif of stylized kokeshi (carved, limbless Japanese dolls), which symbolize the site's registered users, the 'Nima-kai. ${ }^{5}$ Language about community pervades the site. The 'About' page explains:

Discover Nikkei is a community website about Nikkei identity, history and experiences. The goal of this project is to provide an inviting space for the community to share, explore, and connect with each other through diverse Nikkei experiences, culture, and history.

'Community' appears as the third option in the global navigation bar; it points to a main page that invites users to 'Join the Discover Nikkei global community, where Nikkei interact and bond together! Use the tools in the community section to actively share information about your community, wherever it is located.' Practically every page of the site asks online visitors to participate through various options. ('As much as possible, we're trying to push, "How do you become a part of this?,"' Murakami-Tsuda informed me.) Users can set up profiles to become one of the Nima-kai. Nimas submit and comment on stories to the Journal section, use the Nikkei Album to upload media and create visual stories, submit events to an event calendar, or flag content as inappropriate. ${ }^{6}$ People can also get updates about the project through Facebook, Twitter, and e-mail, and are advised they can support the project by donating, promoting it to their social networks, volunteering, and visiting often. The site does not utilize 'real time' information to create a sense of co-presence, but it features recent activity on its homepage and includes a map of where Nima-kai reside.

These efforts have succeeded in creating an online experience that conveys many of the senses of community described above. The site is particularly successful at portraying the diversity and fluidity of Nikkei identity and experience. Writers of different races, ethnicities, generations, and locales produce content that appears in four different languages (English, Japanese, Portuguese, and Spanish). Shared stories range from the historical to the contemporary, from tragic stories of war to funny stories about food and craft. They also highlight experiences of prejudice, resistance, cultural assimilation and hybridity that challenge stereotypes of Japanese and Asians. That the site seeks to empower people to speak for themselves is plainly evident.

The senses of community that Murakami-Tsuda most sought to cultivate-that of a proximal and reciprocal community-are also apparent. Articles are regularly published to the Journal, and while these are mostly the result of the tireless persistence of MurakamiTsuda and former Project Coordinator (now Manager) Yoko Nishimura, to solicit JANM staff, program speakers, and their social and professional networks for contributions, the numbers of submissions from users is growing and may be credited with diversifying the content. ${ }^{7}$ Similarly, 
users sometimes comment on Journal stories and some of these start brief exchanges between author and commenter, or between commenters.

At the same time, the proximal and reciprocal community of frequent, public posters that Murakami-Tsuda hoped for has not yet materialized. Alogfile analyzer reports that the site enjoys a steady traffic of 30,000 to 40,000 unique visitors each month, but few leave publicly visible traces. ${ }^{8}$ In June 2009, the site had 2400 active user accounts; in October 2013, it had 3934 active user accounts. At both times, far fewer contributed content. Conversational exchanges, while they happen, are subdued; my review of the 43 articles published in the Journal in July 2010 counted only 11 comments, while 41 posts in July 2013 received six. While MurakamiTsuda informed me eight months after the launch of the redesign that 'significant growth' had occurred in the Journal and Events with almost daily updates, they were 'still struggling with ... getting people to create accounts, log in, and update their user profile pages.' ${ }^{9}$

These numbers of site visitors versus contributors illustrate the typical 'power law' of social media participation, which describes how a minority of users will regularly generate the majority of content or participate publicly, while the majority of users will participate periodically, if at all (Russo and Peacock 2009). Most of the audience reads and observes. They 'lurk.'

The recent emphasis museums place on communication leads them to lament low numbers of contributions to participatory projects. They interpret lack of contribution as lack of engagement, a logic that understands participants as 'active' and observation as 'passive.' Internet culture and museum practice often perceive lurkers, people who use networked computing without typing themselves into being, with suspicion, as a 'noncontributor,' or even 'someone who is shirking social responsibility' (Shumar and Renninger: 6). Discover Nikkei illustrates the inaccuracy of this view of lurkers and the limitations it places on understanding how people engage with content.

Anecdotal evidence suggests that Discover Nikkei resonates powerfully with many users, even if they do not make themselves visible on the site. Murakami-Tsuda shared a story about the person she believes to be the project's most regular non-staff user, a woman she thinks does not 'even [have] a user account.' The user is a JANM docent, 'an older Nisei'10 who:

[...] reads like every single article on our site. And she prints them out. She prints
them out and reads all our English articles. You know, 'cause sometimes she'll
come up to me and say, 'Oh my god, I really enjoyed that article' [laughing]. And
she even told me, she started printing out the Spanish language articles because
her pastor's wife is like from Puerto Rico or something, and so she started printing
out the Spanish articles and giving it to the pastor's wife to read. And ... she's like,
'You have too much content on there.' It was so funny because she was telling
me, she used to tell her kids, 'You spend too much time on the computer,' and
now she's spending all her time on Discover Nikkei [laughing].

Murakami-Tsuda knows that this type of deep, invisible engagement with the site is likely the norm. She regularly encounters users' appreciation for DN coupled with unwillingness or indifference to showing that appreciation online:

[...] every time I write one of my articles, [...] I try and send the link to my friends and my family to say, 'Oh, my latest article is on, check it out.' Part of it is selfpromotion, but part of it is trying to get them to visit, you know, Discover Nikkei and hopefully they'll look at other stuff while they're there. But, they'll always, they'll e-mail me back and say, 'Oh, you know, I really enjoyed that.' And it's like [laughing], 'Post the comment online!' But I can't get them to post it online, but at least I know that they're reading it and that they're enjoying it. But, you know, she's [referring to the docent] another one, she's like, 'Oh, I really enjoyed that.' Post it online!

The reluctance of DN users to record their engagement on the site understandably frustrates Murakami-Tsuda. As the project lacks an established evaluation framework, feedback would be one of the most obvious ways for her to perceive its value, as well as for the site to manifest its users as a collective audience. Yet, even with publicly active users, metrics programs for 
website interactions are notoriously inaccurate (Chan 2008). Further, comments—often simple statements of thanks - are dim reflections of the actual experience that prompted the contribution.

The emphasis on visible communication that accompanies community in social media reveals itself in this case to be inadequate for understanding the reach and resonance of the site, and suggests the need to redefine community in a more expansive way that could further the project's potential to achieve its goals and suit user needs. Such a process might start by considering more fully how meanings of community circulate and inform the project. When I asked her what she meant by 'community,' Murakami-Tsuda illustrated how this could be helpful as she readily replied with a sophisticated understanding of the concept.

As far as the community, I mean, I think a lot of it is really building a network of individuals and organizations on a global scale that are interested in, sort of, the Nikkei experience. I mean that would be the common sort of bond. But, I think a lot of it, with community, it's really a sense of ownership, feeling that, you know, you have some stake in this larger project or this larger thing - like you know, when you're a member of a church community, when you're a member of a community, it's not a pass... It's not a passive, it's a step beyond a passive thing. It could be passive, but you know, even within a community there's different levels of interaction, right? There's some members where it's a very passive thing, where they just, they just participate. Then there are people who actually help, you know, will volunteer and then there's people who will actually be the ones who are organizing, coordinating. So, I mean, even with a community, you know, there's very diverse roles and I think that applies here too, with websites. The majority of people will never actively participate-they'll just, you know, quietly, just look. But, then there are people who will help, who will actually post things. And then there will be the people who are actually, you know, who help us outreach, and, you know, help us further develop it [...] and, I think, with any comm...-you know, I kind of look at it as, you know, it's like ... a virtual Japantown, kind of, you know? And not every person in a community gets along together [laughs], there's always different opinions and different perspectives, there's all these different elements, but, you know, but there's one thing that really, you know, connects them all together.

This perspective roots community in a sense of interest, belonging, or investment, (however it is perceived by individuals) and acknowledges that it involves different levels and degrees of participation. Such meanings suggest myriad ways to gauge the vitality and value of the project to different users and to the museum. Community viewed in this light also suggests that lack of public participation should not be seen as a problem to overcome, but as a moment in a spectrum of possible interactions. Russo and Peacock (2009) have noted that the active/ passive binary of participation in museums' social media work does not accurately or helpfully convey audience's actual interactions. This reality suggests that museums may benefit by complicating how they see lurkers, which would force a more expansive perspective on community and how they create online participatory experiences to serve the diverse needs of users. A more nuanced view of lurkers would recognize their behavior as already active and valuable. They might be viewed as 'covert learners' who benefit from observation and 'the experience of continued affiliation' that comes from repeat site visits (Nolan and Weiss 2002: 298), a perspective that aligns with educational theory that sees observation as a significant stage of learning (Lave and Wenger 1991). This view also recognizes that lurking can be temporary or periodic behavior. Research suggests that people toggle between participatory options in their online behavior, sometimes lurking, sometimes taking public actions, then returning to lurking (Preece and Shneiderman 2009: 15-16; Kelly and Russo 2008). Lurkers also may quickly move to leadership positions in an online community when they do make themselves visible because they have spent so much time learning the culture and content (Nolan and Weiss 2002: 313).

As Russo and Peacock have asserted, understanding users' motivations for contributing and lurking behooves museums as it can help them use social media to better serve user rather than principally institutional needs. The emphasis on public communication in community 
rhetoric influences museums to concentrate on building participatory features that demand public interaction, when private features might appeal to a larger swathe of users as well as provide an entry point for participation that may lead to more public and pronounced participation, periodically or eventually. Museums also continue to worry that users posting inappropriate content will be a sizeable problem, when institutions running projects that allow users to post anonymously or without moderation routinely report few abuses (Springer et al. 2008: 35-6). Discover Nikkei provides some private features, such as saving Nikkei Albums in draft form or receiving e-mail updates. But, the project might encourage further use and participation by allowing people to comment on posts or tag content anonymously and without registering. Other options would be to let users favorite and make collections of content so they could quickly revisit it to make a comment at a later date or use it for another purpose. The site might also consider starting an advisory board drawn from users, which could help the staff solicit and edit Journal articles. While the board's interactions would not be directly visible on the site, its efforts could add more diverse viewpoints on content and nurture an aspect of the user audience as a proximal community.

Judging social media projects on the basis of public communication also neglects to see how few contributors can create great value for many. This is reflected by the social media power law, but it also bears up under research. Anne Jackson et al. studied the motivations of employees of a multinational corporation who used an internal blogging system. Their findings suggest that large numbers of public participation is not necessary to create value for users in general, whether they engaged at high, medium, or low levels:

[...] it may be that internal blogging communities with a small core of heavy users and a larger group of medium users can provide comparable value to the corporation as a community of all heavy users, and at significantly less cost of time spent blogging by individual employees. (2007: 4)

Further, factoring in people's preferences for participation in social media would spur museums to remember that participation involves risk. Michael Schudson argues that dialogue gets upheld as the 'soul of democratic life' because Western society conceives it as 'spontaneous and free' (1997: 298). He argues that spontaneity is a characteristic suited to social talk-'the pleasure of interacting with others in conversation itself,' which passes between intimates, involves insider lingo, and rewards wit (300). In contrast, spontaneity and freedom do not support 'democratic talk, 'which is oriented towards problem-solving and is essentially public-it occurs in the presence of strangers (305). As strangers will 'miscommunicate because they do not share background knowledge and commitment to common norms,' it always risks 'personal composure' (304).

Viewing public dialogue through this lens reminds us that when museums call for online communication from audience members, they ask them to risk composure and reputation. When designing on-site participatory exhibits, Nina Simon (2010: 1-32) stresses how important it is to explain to visitors the value they are producing and will receive. Museums should consider how well they have explained to the public the value and benefits of their online participation. They should also consider if they have constructed a suitably safe space for that participation. In considering the environment that fosters democratic talk, Schudson rejects spontaneous and open terms and asserts the importance of rules, agreed to by all participants, that 'govern public reasonableness.' Such rules of civility in public discourse 'can help protect the slow of speech, who are otherwise disenfranchised by the articulate and by the glib' (ibid.: 301). Parallels can be found in Facebook's Community Standards, Etsy's Dos and Don'ts, and Science Buzz's Community Guidelines (produced by the Science Museum of Minnesota). These rules or guidelines establish the standards of civil behavior for a site, but as they aren't highly visible aspects or required reading for registration, they are as much about explaining what site managers' will delete as they are about creating civil spaces for interaction. Of course, rules of civility don't make people treat each other well. But, such contrivances broadcast a museum's investment in creating civil social spaces. Making transparent the conditions under which discussion is sought may encourage participation since it suggests someone is moderating online activity and it gives users externally justifiable grounds on which to help moderate interactions (Wise and Hamman 2006: 26, 30, 32). Such attentions relay to audiences 
that a museum is mindful of the risks people take when publicly participating and that they may owe them some support or protection. Further, museums that acknowledge the risk their audiences take by participating in social media may also inspire them to cultivate a stronger culture of reciprocity and take more risks themselves.

\section{Conclusion}

In sum, the power of discourse lies in its ability to steer action, as well as in its ability to shield inaction. Community as a concept and social media as communicative tools and as a cultural force are laden with ideas that can operate as fluffy rhetoric or directive mandate. They can circulate in the everyday life of museums to serve the status quo as easily as they can spur change. Social media clearly have potential to democratize practice in various ways: to increase access to resources; diversify audiences and content; include audience experiences and opinions; encourage dialogue and collaboration; and make internal practices more transparent and responsive (Wong 2012). But, to truly explore this potential requires an experimental and critical approach to the contexts in which these media operate and to the discourse of community they help spread. I thus close with some recommendations aimed at fostering such an approach, including considering how other concepts of online audience may be productive for engaging audiences.

Museum practitioners wishing to construct community through social media should discuss and articulate what community means for a particular project and how those meanings should inform its design, implementation, and evaluation. A project hoping to appeal to a local audience would enable different participatory features and mechanisms than a project meant to attract an online or international audience. Confronting community and social media as discursive objects and tools encourages museum staff to consider the power issues that are inherent in projects that seek to build relationships with audiences: Is the museum naming an audience a community or respecting a group that identifies as such? What draws the group together as a perceived community? What tensions are apparent that speak to different experiences and preferences in the group? Along with formative research with audience members, such questions should determine features for participation and structures of support for that participation. This process asks staff to consider audience desires in relation to institutional goals and provides a check on whether institutional goals are realistic, relevant, or overly ambitious. Such conversations in the design phase of participatory projects would also encourage staff to sketch out frameworks for evaluation from day one. Projects aimed at attracting an extant community of interest or practice would be measured differently than a project trying to appeal to a new audience. Like others that have pointed to the necessity of changing the way museums evaluate their social media efforts (Chan 2008; Russo and Peacock 2009), I support the need for a cumulative view rather than a transactional one. A more holistic approach to the evaluation of a records not only numbers of visitation and interaction, but also performs surveys and interviews of users and staff who interact with the project, since like Murakami-Tsuda they are its most regular observers and participants. Measures of value should also include what museums do with the information communicated to them by audiences, as they would make museums more accountable and more self-reflexive in that they may reveal reasons or methods for changing institutional practices. This perspective would position museums to approach social media not as 'quick fixes' that immediately achieve better audience engagement or more democratic practice. Instead, these ideas ask staff to regard them always as only starting points towards those goals.

Acknowledging that words direct action raises the question of whether there are words for describing audiences interacting with museums through social media that might be more productive for progressive practice. Research on how people interact through computermediated communication has generated multiple ways to conceptualize users collectively. Some of these name groups as different types of communities. For instance, 'online community' acknowledges that internet connections and digital interfaces can bring people together and shape their relationships. Noting that concept is somewhat technologically deterministic, Nancy Baym asserts that 'the key to understanding online and audience communities is to focus on the communicative patterns of participants rather than on the media through and in 
response to which members coalesce' (2000: 5). In her research on online communities, she has avoided a one-dimensional understanding of people's computer-mediated communication by discussing how users can be understood as 'audience communities'-people gathered around a text-and 'communities of practice'-people who engage in shared labor. Further, many scholars utilize the concept of 'networked publics' as a descriptor for 'the ways in which people are networked and mobilized with and through media' (Ito 2008: 2). Mizuko Ito explains this concept 'is an alternative to terms such as audience or consumer. Rather than assume that everyday media engagement is passive or consumptive, the term publics foregrounds a more engaged stance' (3). Like 'community,' 'public' is a term with baggage, but it arguably avoids the overly romantic yearnings of the former. Both 'community' and 'public' convey a sense of commonality, but whereas the former presumes people bond over mutual investment, the latter does not assume why people have similarly directed their attention to an event, a text, etc. Finally, while social media are largely aimed at encouraging public interactions, it is important to remember that these platforms usually allow users to constrain the reach of that publicity to people that they know, or friends of friends, etc. Baym has described 'communities' supported by digitally networked media as 'egocentric communities,' which acknowledges the intensely personal nature of how social media users perceive community. None of our Facebook friends or Twitter followers see the exact same things we do when we log in-we are the hubs in our own personal communities. This idea is based on the concept of 'networked individualism,' which marries the personal to the public in an effort to reflect our modern experience of media. According to Lee Rainie and Barry Wellman, internet and mobile technologies support the building and maintenance of large, diverse, and dispersed social networks in which it is the person who is the focus: not the family, not the work unit, not the neighborhood, and not the social group' (2013: 7). Rainie and Wellman argue that this arrangement can nurture feelings of community, but the concept of networked individualism is helpful to museums because it questions the value of museums expending their always stretched resources trying to draw people into communities where institutions are the hub. Might the engagement and relevance museums seek be better achieved by experimenting with how museums support people in their own extant communities? Today, more than ever, museums are points in the networks in which people seek information, education, and entertainment. Museums serving 'networked individuals' rather than trying to build online communities may be more attentive to the multiplicity of user needs and preferences, and may then design more varied and nuanced ways for them to interact with museum content and other users.

Attending to community as an object of discourse in museum practice ultimately means recognizing its considerable power in reality. Discussions about definitions are not academic. The weight of 'community' convinces boards, donors, and administrators to greenlight projects. But, that weight then does not necessarily drive those projects. Community in museum practice too often works as a smokescreen. Its rhetorical and symbolic power is routinely used to justify decisions, yet, it rarely seems to prompt among practitioners the kind of meaningful conversation from which it is purportedly born. As such, the weightlessness of 'community' means well-meaning projects can end up toothless. One way to prevent that is for practitioners to deeply immerse themselves in the discourses that inform projects that seek to engage the public, including the discourse that surrounds the media that will facilitate that engagement. If museums' goals are to bring audiences and museums into relationships that ensure relevance for all parties, let that practice be built not on rhetoric, but on deliberate and strategic attention to the specific contexts of discourse in which words will become action.

Received: 18 January 2014

Finally accepted: 28 January 2015

\section{Acknowledgements}

The author thanks Vicky Murakami-Tsuda for her kind participation in this research, the peer reviewers for their supportive and constructive comments, and Jessica Wong for her keen copy-editing eye. 


\section{Notes}

1 I draw my evidence from a broad survey from 2008 to 2011 of social media in general and U.S.-based museums' work using external platforms like Twitter and in-house projects that I conducted for my dissertation. Social media has, of course, continued to evolve and some of the projects used as evidence have been redesigned, but as the conventions social media use to construct community are still widely apparent, my comments here are still applicable.

2 Social media sites have recently been de-emphasizing the simultaneity of 'real time' information and are instead highlighting photography. This change comes as smartphone adoption continues to rise and the quality of cameras on smartphones has drastically improved. Photos and videos are increasingly how social media 'show' people to each other as 'real.' For instance, I received an e-mail message from Twitter on June 30, 2013 in which the company promotes the six-second looping videos produced by its newly-acquired application Vine as 'little windows into the people, places and things that make up your life.'

3 A comprehensive history of this project can be found in my dissertation.

4 Vicky Murakami-Tsuda, interview by author, digital recording, 3 April 2009, Los Angeles.

5 Murakami-Tsuda wanted a friendlier term than 'users' to refer to the Discover Nikkei audience and solicited followers of the project's Facebook page for ideas. 'Nima-kai' was suggested as a combination of 'Nikkei' and 'nakama,' Japanese for 'colleagues,' 'fellows,' or 'circle.'

6 Registered users can also tag posts, but that feature is not advertised.

7 Vicky Murakami-Tsuda, Facebook message to author, 1 October 2013.

8 The project uses AWStats to collect web traffic statistics.

9 Vicky Murakami-Tsuda, e-mail response to author, 3 March 2010.

10 Murakami-Tsuda estimates her age in her 80 s since 'she was in camp,' a reference to the Japanese internment camps of World War II.References

\section{References}

Anderson, B. (1991) Imagined Communities: Reflections on the Origin and Spread of Nationalism, London: Verso.

Archibald, R. (2004) The New Town Square: Museums and Communities in Transition, Walnut Creek, Calif.: AltaMira Press.

Arendt, H. (1998) The Human Condition, Chicago: University of Chicago Press.

Barlow, A. (2008) Blogging America: The New Public Sphere, Westport, Conn.: Praeger.

Barrett, J. (1998) 'Community, Public, Audience: Complex and Critical Transactions', in Alison Beale and Annette van den Bosch (eds) Ghosts in the Machine: Women and Cultural Policy in Canada and Australia, 147-162, Toronto: Garamond Press.

Bauman, Z. (2001) Community: Seeking Safety in an Insecure World, Cambridge, Mass.: Polity. 
Baym, N. (2010) Personal Connections in the Digital Age, Cambridge, UK: Polity.

Boyd, d. (2006) 'Friends, Friendsters, and Top 8: Writing Community into Being on Social Network Sites', First Monday 11 (12) http://www.firstmonday.org/issues/issue11_12/ boyd/index.htm, accessed 13 November 2008.

Boyd, d. and Ellison, N. (2007) 'Social Network Sites: Definition, History, and Scholarship', Journal of Computer-Mediated Communication 13 (1) article 11 http://jcmc.indiana. edu/vol13/issue1/boyd.ellison.html, accessed 26 June 2010.

Boyd, d. and Marwick, A. (2011) 'Social Privacy in Networked Publics: Teens' Attitudes, Practices, and Strategies', Oxford Internet Institute http://papers.ssrn.com/sol3/ papers.cfm?abstract_id=1925128, accessed 1 July 2013.

Chan, S. (2008) 'Towards New Metrics Of Success For On-line Museum Projects', in Jennifer Trant and David Bearman (eds) Museums and the Web 2008: Proceedings, Toronto: Archives \& Museum Informatics http://www.archimuse.com/mw2008/papers/ chan-metrics/chan-metrics.html, accessed 16 March 2011.

Cohen, A. (1985) The Symbolic Construction of Community, Chichester: E. Horwood.

Crooke, E. (2007) Museums and Community: Ideas, Issues and Challenges, London: Routledge.

Dana, J. (1919) The New Relations of Museums and Industries: The Story of the First Ten Years of a Group of Experimental Museums, Newark: The Newark Museum Association.

Delanty, G. (2003) Community, London: Routledge.

Donath, J. (1999) 'Identity and Deception in the Virtual Community', in Mark A. Smith and Peter Kollock (eds) Communities in Cyberspace, 29-58, London: Routledge.

Foucault, M. (1995) Discipline and Punish: The Birth of the Prison, translated by Alan Sheridan, New York: Vintage Books.

Ito, M. (2008) 'Introduction', in Kazys Varnelis (ed) Networked Publics, 1-14, Cambridge, Mass, The MIT Press.

Jackson, A., Yates, J. and Orlikowski, W. (2007) 'Corporate Blogging: Building Community Through Persistent Digital Talk', in Proceedings of the Fortieth Annual Hawaii International Conference on System Sciences, 1-10, Waikoloa, Hawaii: University of Hawaii at Manoa.

Jansen, B., Zhang, M., Sobel, K. and Chowdury, A. (2009) 'Twitter Power: Tweets as Electronic Word of Mouth', JASIST 60 2169-2188.

Jones, S. (ed) (1998) CyberSociety 2.0: Revisiting Computer-mediated Communication and Community, Thousand Oaks, Calif.: SAGE Publications.

Karp, I. (1992) 'Introduction: Museums and Communities: The Politics of Public Culture', in Ivan Karp, Christine Mullen Kreamer and Steven D. Lavine (eds) Museums and Communities: The Politics of Public Culture, 1-18, Washington, DC: Smithsonian Institution Press.

Karp, I, Kreamer, C. and Lavine, S. (eds) (1992) Museums and Communities: The Politics of Public Culture, Washington, DC: Smithsonian Institution Press. 
Kelly, L., and Russo, A. (2008) 'From Ladders Of Participation To Networks Of Participation: Social Media And Museum Audiences', in Jennifer Trant and David Bearman (eds) Museums and the Web 2008: Proceedings, Toronto: Archives \& Museum Informatics http://www.museumsandtheweb.com/mw2008/papers/kelly_l/kelly_l.html, accessed 3 November 2013.

Kikumura-Yano, A., Hirabayashi, L. and Hirabayashi, J. (eds) (2005) Common Ground: The Japanese American National Museum and the Culture of Collaborations, Boulder: University Press of Colorado.

Kolko, B., and Reid, E. (1998) 'Dissolution and Fragmentation: Problems in On-Line Communities', in Steven G. Jones (ed) Cybersociety 2.0: Revisiting ComputerMediated Communication and Community, 212-229, Thousand Oaks, Calif.: SAGE Publications.

Lave, J., and Wenger, E. (1991) Situated Learning: Legitimate Peripheral Participation. Cambridge, UK: Cambridge University Press.

Lovejoy, K., and Saxton, G. (2012) 'Information, Community, and Action: How Nonprofit Organizations Use Social Media', Journal of Computer-Mediated Communication 17 337-353.

Manovich, L. (1995) 'From the Externalization of the Psyche to the Implantation of Technology', in Florian Roetzer (ed) Mind Revolution: Interface Brain/Computer, 90-100, Munich: Akademie Zum Dritten Jahrtausend.

Marty, P. (2008) 'An Introduction to Museum Informatics', in Paul F. Marty and Katherine Burton Jones (eds) Museum Informatics: People, Information, and Technology in Museums, 3-8, New York: Routledge.

Nolan, D., and Weiss, J. (2002) 'Learning in Cyberspace: An Educational View of Virtual Community', in K. Ann Renninger and Wesley Shumar (eds) Building Virtual Communities: Learning and Change in Cyberspace, 293-319, Cambridge, UK: Cambridge University Press.

Parry, R. (2007) Recoding the Museum: Digital Heritage and the Technologies of Change, London: New York: Routledge.

Preece, J., and Shneiderman, B. (2009) 'The Reader-to-Leader Framework: Motivating Technology-Mediated Social Participation', Transactions on Human-Computer Interaction 1(1) 13-32.

Russo, A., and Peacock, D. (2009) "Great Expectations: Sustaining Participation in Social Media Spaces', in Jennifer Trant and David Bearman (eds) Museums and the Web 2009: Proceedings, Toronto: Archives \& Museum Informatics, http://www. museumsandtheweb.com/mw2009/papers/russo/russo.html, accessed 7 August 2013.

Schudson, M. (1997) 'Why Conversation Is Not the Soul of Democracy', Critical Studies in Media Communication 14 297-309.

Shirky, C. (2008) Here Comes Everybody: The Power of Organizing Without Organizations, New York: Penguin Press.

Shumar, W., and Renninger, K. (2002) 'Introduction: On Conceptualizing Community', in K. Ann Renninger and Wesley Shumar (eds) Building Virtual Communities: Learning and Change in Cyberspace, [page numbers here please], Cambridge, UK: Cambridge University Press. 
Slater, D. (2002) 'Making Things Real: Ethics and Order on the Internet', Theory, Culture \& Society 19 (5/6) 227-245.

Springer, M., Dulabahn, B., Michel, P., Natanson, B., Reser, D., Woodward, D. and Zinkham, H. (2008) For the Common Good: The Library of Congress Flickr Pilot Project, Washington, DC: Library of Congress.

Sundén, J. (2003) Material Virtualities: Approaching Online Textual Embodiment, New York: Peter Lang.

Tchen, J.. 'Creating a Dialogic Museum: The Chinatown History Museum Experiment', in Ivan Karp, Christine Mullen Kreamer and Steven D. Lavine (eds) Museums and Communities: The Politics of Public Culture, 285-326, Washington, DC: Smithsonian Institution Press, 1992.

Watson, S. (ed) (2007) Museums and Their Communities, London: Routledge.

Williams, R. (1983) Keywords: A Vocabulary of Culture and Society, New York: Oxford University Press.

Wise, J. (2003) 'Community, Affect, and the Virtual: The Politics of Cyberspace', in Beth E. Kolko (ed) Virtual Publics: Policy and Community in an Electronic Age, 112-133, New York: Columbia University Press.

Wise, K., and Hamman, B. (2006) 'Moderation, Response Rate, and Message Interactivity: Features of Online Communities and Their Effects on Intent to Participate', Journal of Computer-Mediated Communication 12 (1) article 2 http://jcmc.indiana.edu/vol12/ issue1/wise.html, accessed 8 July 2012.

Wong, A. (2011) 'Museums, Social Media, and the Fog of Community', PhD diss., University of Maryland.

Wong, A. (2012) 'Social Media Towards Social Change: Potential and Challenges for Museums', in Richard Sandell and Eithne Nightingale (eds) Museums, Equality and Social Justice, 281-293, London: Routledge.

Young, I. (1986) 'The Ideal of Community and the Politics of Difference', Social Theory and Practice 12 (1) 1-26.

\section{Amelia Wong*}

Amelia Wong holds a B.A. in History/Art History from UCLA and a Ph.D. in American Studies from the University of Maryland, College Park. She has held several positions in the arts and cultural sectors and in higher education in the Los Angeles and Washington, DC areas, including managing social media outreach and developing web content at the United States Holocaust Memorial Museum and developing and teaching the digital media curriculum for the Museum Studies Program at The George Washington University. She consults for organizations regarding technology, education, audience engagement, and storytelling.

Amelia Wong

4224 Stewart Ave.

Los Angeles, CA 90066

ameliaswong@gmail.com

301.442.7219 